\title{
Storage of Renewable Electricity through Hydrogen Production
}

\author{
Christoph Stiller ${ }^{1}$, Patrick Schmidt ${ }^{1}$, Jan Michalski ${ }^{1, *}$ \\ ${ }^{1}$ Ludwig-Bölkow-Systemtechnik GmbH, Daimlerstr. 15, 85521 Munich/Ottobrunn, Germany \\ * Corresponding author.Tel: +49 8960811041,E-mail:christoph.stiller@LBST.de
}

\begin{abstract}
With more than $20 \mathrm{GW}$ of installed wind power capacity installed in Northern Germany and more to come when offshore wind power expands, there are periods when the available wind power exceeds the grid capacity or even the electricity demand in reach. This excess wind power could be utilised for the electrolytic production of hydrogen, which can be stored and used as a transportation fuel, feedstock for the chemical industry, for re-electrification or for natural gas (NG) pipeline injection.

Based on the potential availability of excess wind power for hydrogen production and in view of the expected build-out, the paper drafts and discusses the economic framework and modalities of hydrogen production. Potential usages are discussed in general and specially for Northern Germany, where a hydrogen demand of 320 mill. $\mathrm{Nm}^{3}$ was identified by 2020 for industry and transportation.

With some initial incentives, electrolytic hydrogen production can be made competitive by 2020. It is concluded that Northern Germany is an ideal region for the production of hydrogen from renewables due to the its high wind power density, its geologic conditions allowing for cavern storage, its industrial demand for hydrogen and also its pioneering role in hydrogen fuelled road transportation.
\end{abstract}

Keywords: Hydrogen, Storage, Electrolysis.

\section{Introduction}

With the increasing renewable power capacity, especially wind power, installed in many countries, there will be periods when the available power exceeds the capacity of the grid or even the demand in reach. This excess electricity may be eliminated by cutting down renewable power feed-in or, more advantageously, by adding additional temporal demand through electricity storage devices. In countries without excessive potential for pumped hydro storage, the storage technology with the highest energetic potential is offered by hydrogen. Hydrogen can be produced from electricity by water electrolysis and stored inexpensively in underground salt caverns where geologic conditions are suitable, or at higher costs in aboveground pressure vessels or liquid dewars. The hydrogen can be used for power generation when renewable generation is low, but also as a transportation fuel, as a feedstock for the chemical industry or other purposes. Therewith, hydrogen not only makes renewable electricity storable over long periods but also creates cross-links to other energy-intensive sectors.

This paper presents the main results of a recent study on the potentials of hydrogen production from wind power in Northern Germany [1], where more than $20 \mathrm{GW}$ of wind power capacity are installed today and there will be tremendous increases in the coming years due to the expansion of offshore wind power. It will first review the current framework of the German electricity generation. Then, based on the expected electricity generation and demand, the amount of excess power available for hydrogen production will be estimated. This will be followed by a discussion of operation models for hydrogen electrolysis, rounded off by a discussion of required storage demand and possible uses and costs of the hydrogen.

\section{General framework of the German electricity generation}

Since 1990, electricity production in Germany has only increased by about $0.8 \%$ p.a. on average, and almost the entire surplus has been covered by renewable electricity [2]. 
Due to the age structure of the power plant park and in view of the previously planned nuclear phase-out, currently a large number of new fossil power plant projects (especially hard coal) are in the planning phase; yet, it needs to be mentioned that the realization of many projects is becoming ever more uncertain, partly due to the postponement of the nuclear phase-out but also due to decreasing public acceptance for infrastructure projects [3].

The share of renewables for electricity production in Germany has increased from 10 to 15\% in only three years (2005-2008), and for 2011 the Transmission System Operators (TSOs) expect a total of 112 TWh renewable electricity, representing almost $20 \%$ of overall production [4]. Highest shares are being achieved in the North (e.g., in Schleswig-Holstein, renewable energy generation, mainly wind power, exceeds $40 \%$ of the electricity demand). Specifically in regions with high intermittent renewable capacities installed, already today grid capacity issues occur and wind turbine power need to be cut off temporarily in order not to cause grid breakdown (regulated in the renewable energy law as "feed-in management") [5]. Further extensive renewable potentials lie within repowering of onshore wind farms and the build-out of offshore wind energy use in the North and Baltic Sea.

By 2020, according to the "Lead scenario 2009" [6], 33 GW from onshore and 9 GW from offshore wind power are expected to be fed into the German grid. The offshore feed-in is expected to grow to $24 \mathrm{GW}$ by 2030. Since all offshore capacity is landed in Northern Germany (mainly in Schleswig-Holstein and Lower Saxony) where also the density of onshore generation is high, this will at times cause massive excess power production. This implies grid reinforcement and extension to transmit the power to neighboring regions; however, even Germany-wide power production may exceed the demand and export capacities at times of low load and high wind.

Possible remedies are the temporal shift of loads by demand-side management and battery electric vehicles; however, potentials are limited both with respect to quantities and time periods over which the loads can be bridged [7]. Therefore, large-scale electricity storage will be urgently required in order to more easily integrate the further increase in intermittent renewable electricity generation into the grid.

\section{Availability of excess power for hydrogen production}

In order to analyse the potentials of hydrogen production from excess renewable electricity, the quantities of power surplus have to be estimated. In this sense "excess power/electricity" will be defined as the portion of power/electricity which cannot be utilised in times of high generation (renewable+fossil+nuclear) and low demand as well as export capacities of a region. In such cases the renewable generation will have to be cut off in order to assure grid stability. The quantity of excess power production depends mainly on the following four factors:

- Installed capacity of intermittent renewables, especially wind power. The feed-in of photovoltaics is less relevant in this context as it provides electricity during daytime where demand is comparatively high.

- Installed capacity of conventional power plants, especially base load plants. In particular, lignite and nuclear power plants are operated at high load also in times of high winds increasing the excess power. For example, during the night of October 4th, 2009, high wind volume and low electricity demand resulted in the negative spot market price of $0.50 € / \mathrm{kWh}$. Since at this time German nuclear power plants still operated at an average load of $77 \%$, lignite at $65 \%$, hard coal at $12 \%$ and natural gas at 
9\% [8] we assume this capacity utilization as the minimum practical part load of conventional plants during situations with excess electricity.

- Electricity demand and demand profile of the region. In general, the excess electricity can be reduced either by demand-side management or by an increased demand for a given level of power supply.

- Export capacity to neighbour regions. This is not only limited by the available transfer capacities, but also by the fact that adjacent regions are meteorologically linked. In this sense, excess wind power generation may occur not only in Northern Germany but also in other regions with own wind parks. In consequence, extension of grid capacity alone is not always effective to reduce excess power.

For the calculation of the excess power, specific assumptions regarding the capacity of energy generation per type and demand curves had to be made. The minimum generation of dispatchable power plants was derived from the estimated available capacity and the minimum part load numbers mentioned above. Onshore wind power curves were based on scaled Germany-wide production curves of the reference year 2008. Wind speed data from FINO platforms in the North and Baltic Sea were used in order to calculate the offshore power curves based on the characteristics of a $5 \mathrm{MW}$ turbine. To estimate the electricity demand, hourly data from 2008 provided by UCTE / ENTSOE [9] were scaled to the respective future demand. Due to metrological linkages between adjacent regions, electricity export to neighbour countries was not considered as a way to use excess electricity. From the comparison of resulting generation and demand, the excess power generation could be estimated as shown in Figure 1.

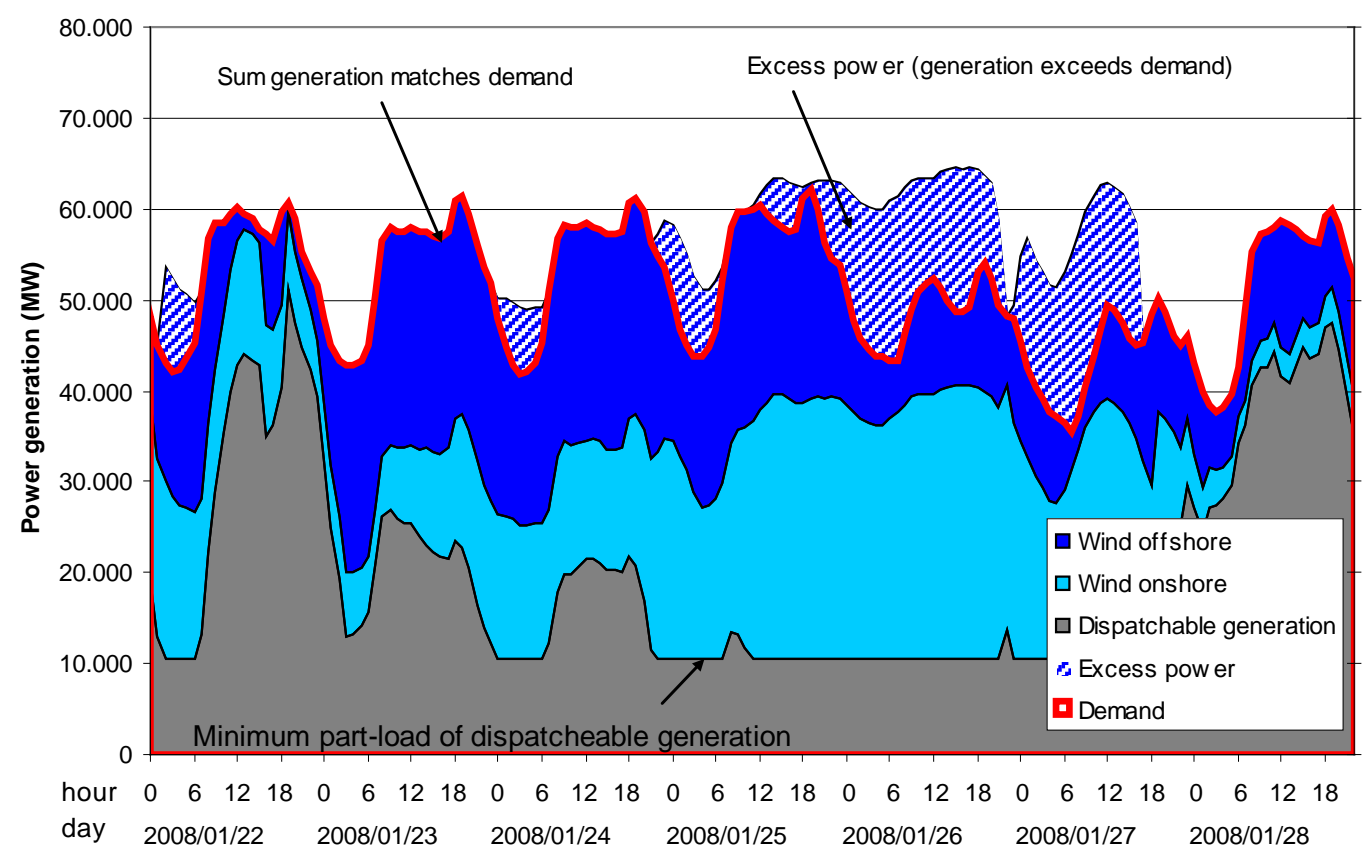

Fig. 1. Methodology to determine excess power (1 week displayed)

With this methodology, the excess electricity was estimated for different scenarios based on the generation and demand projections of the "Lead scenario 2009" [6]. Two variations from the lead scenario were considered: a scenario where $15 \mathrm{GW}$ nuclear generation capacity would remain online (compensated by lower capacities of hard coal and natural gas), and an extreme scenario where the 2008 values for fossil and nuclear generation capacity and demand were frozen and the onshore and offshore generation capacity ramped up as in the 
Lead scenario (33 GW onshore + 9 GW offshore by 2020, and 36 GW onshore + 24 GW offshore by 2030). Figure 2 shows the resulting excess power generation per year in Germany until 2030. In the lead scenario, only up to 9 TWh of excess electricity accrue until 2030 due to the consequent phase-out of fossil power plants. Retaining nuclear capacities will strongly increase excess electricity, and assuming that the power plant park of 2008 is retained while ramping up renewables, huge amounts of excess electricity will accrue until 2030. According to this estimation, by 2020 between 1.1 and 13 TWh of electricity (corresponding to 1.1-13\% of overall wind power generation) cannot be used when they accrue and will therefore be available for energy storage in the form of hydrogen. For comparison, other authors with similar approaches have concluded that for whole Europe, 16 to 260 TWh excess power would accrue by 2020 [10]. Wietschel et al. [11] found that for Germany, 9 TWh excess power would accrue with $38.3 \mathrm{GW}$ wind power installed, increasing to 28 TWh with 48.3 GW wind power installed.

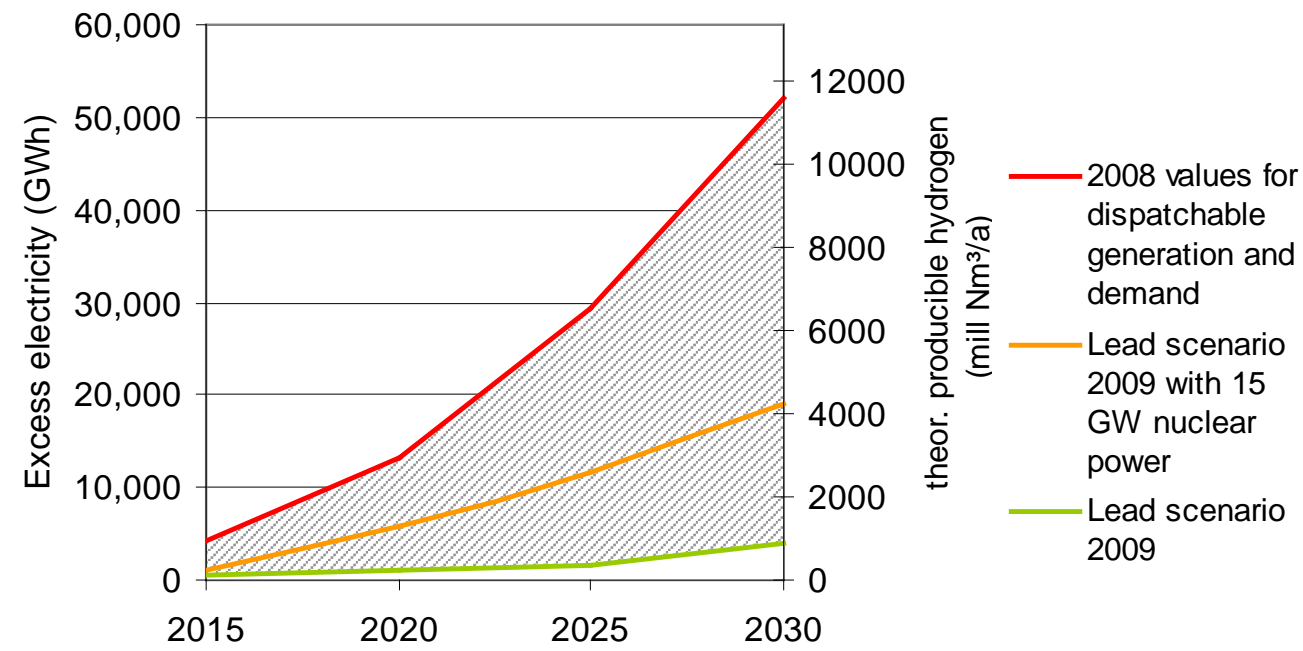

Fig. 2. Resulting excess power generation in Germany through 2030

\section{Operation model for hydrogen production}

Northern Germany is generally an ideal location for hydrogen production from renewables and large-scale storage due to the high concentration of wind power capacity and the geologic conditions facilitating the construction of underground salt caverns suitable for hydrogen storage. With the aim to develop a sound operation strategy for hydrogen production based on the use of excess electricity while at the same time unstraining the grid in the most economic way, the location of electrolysers as well as the economics of purchasing electricity (i.e. the connection to the electricity market) are the main criteria to be addressed.

In general there are three major options for the allocation of electrolysers: directly at the larger on- and offshore wind farms, at the end user location (e.g., an industrial sites or a hydrogen refuelling station) or at grid hubs of the high or ultra-high voltage grid in the areas with the highest wind loads and the heaviest loads on the grid (e.g., along the west coast of Schleswig-Holstein). Placement directly at the wind farms helps to unstrain the electric grid regionally and super-regionally, but hydrogen production is dispersed and the distribution to the consumers is comparatively complex, especially from offshore locations. Placement directly at the consumer site omits the transportation of hydrogen, but does not unstrain the electric grid between the wind farm and the consumer. Furthermore, access to large-scale storage caverns for longer-term storage of hydrogen cannot be provided easily in either of the distributed placement strategies. Therefore we assume that placing larger electrolysis plants at 
grid hubs in areas with high wind power capacity is most beneficial, since this concept effectively unstrains the electric grid and allows for access to large-scale storage and efficient distribution of the produced hydrogen. The maximum electrolysis capacity installed at the grid hubs should be limited to a certain share of the upstream wind power. Figure 3 shows the scheme of a large-scale hydrogen storage plant (re-electrification by either CCGT or fuel cell is optional).

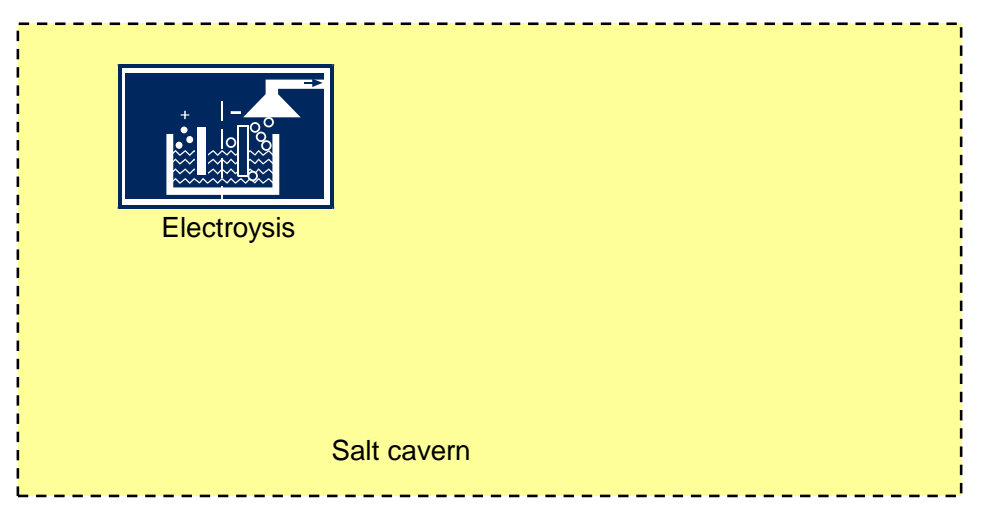

Fig. 3. Scheme of a hydrogen storage plant with optional re-electrification

As a price basis for the required electricity, either the feed-in tariffs for renewable electricity, or the day-ahead spot market hourly price curve of the European Energy Exchange (EEX) are reasonable. The latter can be interpreted either as purchasing the power at the EEX or directly from the wind farm operators, who otherwise would trade at EEX. Today, most wind power is fed in according to the fixed feed-in tariffs regulated by the German Renewable Energy Law. However, it can be expected that by 2020 the fixed feed-in tariffs will have been changed into market premiums, and most wind power will be directly traded at the spot market. Moreover, the spot market price represents the balance between electricity demand and supply: in times of low demand and high renewable energy generation the spot market price will be low, and vice versa. Hence, taking the spot market price as a base for electricity purchases ensures the operation of electrolysers in a way which indirectly unstrains the grid by using the excess electricity at low costs. As a simple operation strategy, electrolysers may be operated at full load during hours when the price is below a certain threshold, and may be kept in warm standby mode when the price is above the threshold. The number of operation hours per year and the average electricity price paid then depend on the price threshold set.

Further revenues for hydrogen producers can result from control reserve, since electrolysers represent a controllable load within the power grid. An electrolyser can be turned off or switched on upon request in order to provide positive or negative control reserve. The provision of the so-called "minute reserve" is tendered jointly by the transmission system operators (TSO) in Germany in 4-hour blocks for the following day. It is important to mention that the pure provision of control power (without actually being called) is already compensated by a per-MW rate. While tendering for control reserve brings additional revenues to the hydrogen production, it also increases the administration effort; since the control reserve is awarded at 10:00 AM for the next day, and the day-ahead spot market auction is at noon, the operator has to rely on a forecast of the spot market price in order to 
decide whether the electrolyser should be operated during every 4 hour block (i.e. tender positive control reserve), or not (i.e. tender negative control reserve). Once control reserve has been awarded, the electrolyser must be operated according to the plan, even if electricity prices differ from the forecast. Therefore and due to the implication to operate in 4-hour blocks, the average electricity price levels will be somewhat higher if control reserve is to be provided.

A further benefit for the hydrogen producers can be achieved by directly utilising stranded wind power from turbines which otherwise would need to be temporarily cut down due to local grid restrictions (so-called "feed-in management"), provided that there are no grid restrictions between the wind turbines and the electrolysers. However, the TSOs are obliged to reinforce the power grid in order to avoid such events; hence, the potential benefits from this strategy are limited and uncertain.

\section{Required storage demand, options for usage of the hydrogen, and costs}

A strategy as described above will lead to a variable electrolyser utilisation with a tendency to higher production in the winter time with high wind power feed-in. In order to optimally level out the seasonal variations in production and facilitate a constant delivery of hydrogen to the end customers we found that a hydrogen storage capacity of approximately 700 full load hours is needed. If the hydrogen consumption can be adapted to the availability (higher consumption in winter than in summer), the storage capacity can be lower; on the other hand, if the hydrogen consumption is inflexible and peaks in summer, the storage capacity will need to be higher. Generally, the economic optimum of design storage capacity will be a trade-off between storage costs and timely flexibility of electrolysis operation (leading to savings in electricity costs). In the case of large-scale storage in salt caverns, the storage only contributes a minor part to the overall costs; however, if storage in e.g. aboveground pressure vessels or liquid hydrogen dewars is chosen, then the costs will be a multiple of the electrolysis costs.

A viable use of the renewable hydrogen is the partial or complete substitution of hydrogen generated from natural gas for uses in chemical and process industry. Besides saving fossil primary energy for hydrogen production by reforming, this has the potential to reduce the greenhouse gas emissions of the industries, improving their carbon footprint and avoiding costs of $\mathrm{CO}_{2}$ certificates. Furthermore, hydrogen-powered road transportation will be an emerging market in the mid term. Offering renewable hydrogen at the refuelling stations to be erected is an interesting option, especially when considering the fact that the consumers might prefer "green hydrogen" and could also be forced by legislation (California has already implemented a law that $33 \%$ of all hydrogen for transportation will need to be renewable).

By screening the hydrogen consuming industry and using estimates on the hydrogen demand for road transportation, we have identified a demand potential of about 320 mill. $\mathrm{Nm}^{3}$ hydrogen from wind power in the federal states Hamburg and Schleswig-Holstein by 2020 [1]. Based on lower heating value, this represents an energy of $960 \mathrm{GWh}$, which equals about $4.5 \%$ of the overall industrial final energy use in this region today. For the production and distribution of the hydrogen, about 1.55 TWh of electricity would be needed per year that could be predominantly supplied from excess electricity. The use of the this amount of renewable hydrogen in industry and transportation in Hamburg and Schleswig-Holstein instead of fossil hydrogen would save about 320.000 tons of $\mathrm{CO}_{2}$-equivalent emissions. Beyond this, there might be potential to export renewable hydrogen, e.g. as a transportation fuel to other regions in Europe. 
Based on current technology, the specific costs of hydrogen production from wind energy in Schleswig-Holstein including distribution will, depending on quantity and location of the consumption, amount to $0.42-0.75 € / \mathrm{Nm}^{3}$ by 2020 (0.14-0.25 $€ / \mathrm{kWh}$ of lower heating value). This is about $0.12-0.32 € / \mathrm{Nm}^{3}$ more than the cheapest supply from fossil energy sources today. However, in the case of an incentive-supported early implementation of electrolytic hydrogen production, hydrogen from wind energy can become competitive by 2020, mainly through the rise of fossil energy prices and the cost reduction potentials of electrolysis.

A further use of the hydrogen could be used for power generation (so-called re-electrification) in combined cycle gas turbines or fuel cells. Re-electrification is a way to stabilise the electric grid by not only taking away power in times of excess renewable electricity but also providing backup power to compensate lack of renewable generation, e.g. in times of low wind. Cofiring gas turbines with natural gas at flexible shares is technically feasible. Also, the injection of hydrogen into the natural gas grid to substitute a certain part of the natural gas is possible. Almost all NG end users can tolerate hydrogen fractions up to $5 \%$ by volume (representing $1.6 \%$ by energy) without modifications. From the NG grid perspective, mainly the process gas chromatographs will have to be modified in order to detect hydrogen. In a future scenario, also up to $20 \%$ by volume hydrogen could be admixed to natural gas [12].

\section{Conclusion}

The paper showed that due to the ongoing build-out of intermittent renewable generation capacity and limited part-load ability of dispatchable power plants, significant amounts of excess electricity will accrue in the German electricity system in the future. This excess energy may be used to generate hydrogen, which can then be economically stored in largescale salt caverns and utilized in industry and transportation sector or for electricity generation at times of low feed-in of renewables. An operation model based on central electrolysis plants at grid hubs, the spot market as a price basis for electricity purchases and a threshold-price strategy can yield minimum overall hydrogen production costs and at the same time facilitate effective unstraining of the grid.

Northern Germany is an ideal region for the production of hydrogen from renewables due to the its high wind power density, its geologic conditions allowing for cavern storage, its industrial demand for hydrogen and also its pioneering role in hydrogen fuelled road transportation (Berlin, Hamburg). Hydrogen storage is the only technology that can provide sufficient storage potential (multi-TWh) in Germany for a fully renewable electricity system. With some initial incentives, electrolytic hydrogen production can be made competitive within some years after the start of its deployment.

\section{References}

[1] C. Stiller, P. Schmidt, J. Michalski, R. Wurster, U. Albrecht, U. Bünger, M. Altmann, Potenziale der Wind-Wasserstoff-Technologie in der Freien und Hansestadt Hamburg und in Schleswig-Holstein. A study commissioned by Wasserstoffgesellschaft Hamburg e.V., Free and Hanseatic city of Hamburg (represented by the Administration of Urban Development and Environment), and the federal state of Schleswig-Holstein (represented by the Ministry of Science, Economics and Transport). Ludwig-Bölkow-Systemtechnik, March 2010. Available at: http://www.h2hamburg.de/index.php?page=download.

[2] M. Reichmuth, G. Schröder, R. Pohl, A. Scheuermann, A. Schiffler, A. Weber, Jahresprognose 2011 zur deutschlandweiten Stromerzeugung aus regenerativen 
Kraftwerken. Available at: http://www.eeg-kwk.net/cps/rde/xbcr/eeg_kwk/2010-10-12IE-EEG-Jahresprognose2011.pdf

[3] Hamburger Abendblatt, 11 December 2009: Climate protectors cheer: No power plant in Lubmin (in German: "Klimaschützer jubeln: Kein Kraftwerk in Lubmin”).

http://www.abendblatt.de/wirtschaft/article1304949/Klimaschuetzer-jubeln-KeinKraftwerk-in-Lubmin.html

[4] Arbeitsgemeinschaft Energiebilanzen e.V.: Electricity generation by energy carriers 1990 to 2008 (in TWh) Germany, Status 27 May 2009; http://www.agenergiebilanzen.de/viewpage.php?idpage $=65$

[5] Act Revising the Legislation on Renewable Energy Sources in the Electricity Sector and Amending Related Provisions - Renewable Energy Sources Act (EEG 2009) -official document, Federal Law Gazette (Bundesanzeiger) 2008 I No. 49, Bonn, 31 October 2008, p. 2074.

[6] German Federal Ministry for the Environment, Nature Conservation and Nuclear Safety: Lead scenario 2009.

http://www.bmu.de/files/pdfs/allgemein/application/pdf/leitszenario2009.pdf

[7] M. Klobasa, Nachfrageseitige Regelungsmöglichkeiten im Energiesystem; in: EnInnov 08, 10. Symposium Energieinnovation. Energiewende: 13.-15. Februar 2008; TU Graz: Verlag der TU Graz, 2008; ISBN: 978-3-902465-94-8, pp. 89-90

[8] EEX Transparency data, power plant information (visited October 2009); available at: http://www.eex.com/en/Transparency/Power\%20plant\%20information

[9] European Network of Transmission System Operators for Electricity: Hourly load values of a specific country for a specific month; available at:

http://www.entsoe.eu/index.php?id=92, visited October 2009

[10]C. Hoffmann, M. Greiner, L. Von Bremen, K. Knorr, S. Bofinger, M. Speckmann, K. Rohrig, Design of transport and storage capacities for a future European power supply system with a high share of renewable energies. IRES Conference 2008, Berlin, 24-25 November 2008.

[11] M. Wietschel, U. Hasenauer, N. Juncà Vicens, M. Klobasa, P. Seydel, Ein Vergleich unterschiedlicher Speichermedien für überschüssigen Windstrom. Zeitschrift für Energiewirtschaft 30 (2006) 2, pp. 103-114.

[12]J. Hüttenrauch, G. Müller-Syring, Zumischung von Wasserstoff zum Erdgas. EnergieWasser-Praxis 10/2010, pp. 68-71; available at: http://www.gatdvgw.de/fileadmin/gat/newsletter/pdf/pdf_2010/03_2010/internet_6871_Huettenrauch.pdf 